\title{
The Nightingale Prize 2011 for best MBEC paper in 2010
}

\author{
Jos A. E. Spaan
}

Received: 7 November 2011/Accepted: 9 November 2011/Published online: 18 November 2011

(C) The Author(s) 2011. This article is published with open access at Springerlink.com

The first Editor in Chief of Medical \& Biological Engineering \& Computing, MBEC was Alfred Nightingale. In 1963 , he died at the age of 40 and therefore has not seen much of his accomplishments for the journal [16]. He was a promising scientist and pioneer in the field of electromyography [12]. In his honor, the Nightingale prize was established in cooperation between the Institute of Physics and Engineering in Medicine ${ }^{1}$ and the International Federation of Medical and Biological Engineering. ${ }^{2}$

The Nightingale prize is intended to bring a paper that has been published recently to attention. Biomedical engineering papers do not collect citations so fast to allow citation frequency to be used as a selection criterion [10, 17]. Hence, we selected those that received a priority of $90 \%$ or higher from the reviewers [18]. We excluded papers from the special issue [9]. The final list consisted out of 10 papers that will be highlighted by this editorial.

The selected winning paper of this year is by Carlos Guerrero-Mosquera, Armando Malanda Trigueros, Jorge Iriarte Franco ans Ángel Navia-Vázquez from the department of Signal Processing and Communications, University Carlos III of Madrid, Madrid, Spain. The paper is entitled: New feature extraction approach for epileptic EEG signal detection using time-frequency distributions [6]. One of the reviewers wrote: "The main strength of the paper is that it presents a new method for reliable automatic detection of an epileptic seizure from EEG signals, taking into account the computational cost of the method applied. Special attention was paid to the removal of

\section{J. A. E. Spaan $(\bowtie)$}

Department of Biomedical Engineering and Physics, Academic

Medical Center, University of Amsterdam, P.O. Box 22700,

1100 DE Amsterdam, The Netherlands

e-mail: jaespaan@gmail.com artifacts in order to distinguish between real epileptic seizures and artifacts during non-epileptic events." In selecting this paper from Carlos Guerrero-Mosquera et al. as the winner, the clinical applicability of the study has played a role.

MBEC is the journal of the International Federation of Medical and Biological Engineering and aims to serve the Biomedical Engineering community at large. This is also apparent from the wide variety of areas represented in the shortlist for the Nightingale price. Although some disciplines are traditionally strongly represented other disciplines come in waves such as the recent one on sleep disorders [2]. The editors see this as a sign of health of the Journal since apparently we serve as a medium for rather actual research topics that have difficulty in finding the right subspecialty journal. However, also the broader audience that is reached by our journal may be a reason of selecting MBEC as the journal of choice.

Several papers related to the cardiovascular system were on the shortlist for the Nightingale price. Biventricular pacing has become an established method for the treatment of heart failure and the paper of Di Molfetta et al. [4] contributes to its effectiveness by comprehensive numerical modeling. The ECG remains an important signal for patient monitoring also during interventional MRI procedures. However, the ECG signal can be strongly affected by gradients-induced artifacts. Sansone et al. [13] analyzed the performance of a specific filtering technique to overcome these problems. With the application of vein grafts, it is important to have quantitative knowledge on focal intimal hyperplasia since this leads typically to graft stenosis. Such a quantitative method was achieved by Franz et al. [5]

\footnotetext{
${ }^{1}$ (http://www.ipem.org.uk/ipem_public).

2 (http://ifmbe.org/).
} 
via a constraint-based cluster analysis. The paper of van Horssen et al. reports on improvements on the detection of fluorescent microspheres and cast material for the quantification of the structure of the coronary vascular bed by an imaging cryomicrotome [20], an instrument that was first described in MBEC [19]. An interesting paper addressed the modulation of a heart rate variability by listening to music [11].

The other papers in the shortlist where all focused on very important issues. In muscular disorders, single muscle fibers are successively lost during the progress of the disease noticeable by an increased fiber diameter variation, fibrosis, and perifasicular atrophy. Istenič et al. [7] developed a method for automated surface EMG classification of such disorders based on a multi-scale entropy-based approach. Temperature reduction of only $1-2^{\circ} \mathrm{C}$ in the brain tissue has the potential to preserve brain function and protect against ischemic injury. Smith and Zhu [14] provided a theoretical analysis of brain hypothermia induced by cold spinal fluid applying a torso cooling pad.

In elderly, paralyzed, and immobilized patients pressure ulcers form a serious risk for skin damage which may result in severe complications. Sopher and Gefen [15] modeled the effects of skin wrinkles, age, and wetness on mechanical loads in the stratum corneum aiming at understanding the parameters in ulcer development such as frictional force and shear stress. Last to discuss but not the least in terms of judgment is the paper of Joshi and $\mathrm{Hu}$ [8] on electroporation focusing on pore shape due to ultrashort electrical pulsing. Electroporation is a topic that has received attention in the journal and probably will attract more papers in the coming years because of its increasing clinical applicability [1,3].

On behalf of the editors, IPEM and IFMBE, I wholeheartedly congratulate the winner of the Nightingale Prize 2011. However, also the other top scorers should be congratulated with their excellent contributions.

As always, we are grateful to IPEM and IFMBE for maintaining the Alfred Nightingale Prize.

Open Access This article is distributed under the terms of the Creative Commons Attribution Noncommercial License which permits any noncommercial use, distribution, and reproduction in any medium, provided the original author(s) and source are credited.

\section{References}

1. Chen C, Smye SW, Robinson MP, Evans JA (2006) Membrane electroporation theories: a review. Med Biol Eng Comput 44: 5-14. doi:10.1007/s11517-005-0020-2

2. Chervin RD, Burns JW (2011) Engineering better sleep. Med Biol Eng Comput 49:623-625. doi:10.1007/s11517-011-0777-4
3. Corovic S, Zupanic A, Kranjc S, Al Sakere B, Leroy-Willig A, Mir LM, Miklavcic D (2010) The influence of skeletal muscle anisotropy on electroporation: in vivo study and numerical modeling. Med Biol Eng Comput 48:637-648. doi:10.1007/ s11517-010-0614-1

4. Di Molfetta A, Santini L, Forleo GB, Cesario M, Tota C, Sgueglia M, Sergi D, Ferrari G, Romeo F (2010) Use of a comprehensive numerical model to improve biventricular pacemaker temporization in patients affected by heart failure undergoing to CRT-D therapy. Med Biol Eng Comput 48:755-764

5. Franz T, Reddy BD, Human P, Zilla P (2010) A mathematical method for constraint-based cluster analysis towards optimized constrictive diameter smoothing of saphenous vein grafts. Med Biol Eng Comput 48:519-529

6. Guerrero-Mosquera C, Trigueros AM, Franco JI, Navia-Vazquez A (2010) New feature extraction approach for epileptic EEG signal detection using time-frequency distributions. Med Biol Eng Comput 48:321-330

7. Istenic R, Kaplanis PA, Pattichis CS, Zazula D (2010) Multiscale entropy-based approach to automated surface EMG classification of neuromuscular disorders. Med Biol Eng Comput 48:773-781

8. Joshi RP, Hu Q (2010) Analysis of cell membrane permeabilization mechanics and pore shape due to ultrashort electrical pulsing. Med Biol Eng Comput 48:837-844

9. Lim CT, Han J, Guck J, Espinosa H (2010) Micro and nanotechnology for biological and biomedical applications. Med Biol Eng Comput 48:941-943

10. Opthof T (2011) Differences in citation frequency of clinical and basic science papers in cardiovascular research. Med Biol Eng Comput 49:613-621. doi:10.1007/s11517-011-0783-6

11. Orini M, Bailon R, Enk R, Koelsch S, Mainardi L, Laguna P (2010) A method for continuously assessing the autonomic response to music-induced emotions through HRV analysis. Med Biol Eng Comput 48:423-433

12. Rémond A (1963) Dr. A. Nightingale, 1923-1963. Med Biol Eng Comput 1:159-160

13. Sansone M, Mirarchi L, Bracale M (2010) Adaptive removal of gradients-induced artefacts on ECG in MRI: a performance analysis of RLS filtering. Med Biol Eng Comput 48:475-482

14. Smith KD, Zhu L (2010) Brain hypothermia induced by cold spinal fluid using a torso cooling pad: theoretical analyses. Med Biol Eng Comput 48:783-791

15. Sopher R, Gefen A (2011) Effects of skin wrinkles, age and wetness on mechanical loads in the stratum corneum as related to skin lesions. Med Biol Eng Comput 49:97-105

16. Spaan JA (2007) The nightingale prize for the best scientific paper published in MBEC 2006. Med Biol Eng Comput 45:1161-1162. doi:10.1007/s11517-007-0287-6

17. Spaan JA (2009) Biomedical engineering and bibliometric indices for scientific quality. Med Biol Eng Comput 47:1219-1220

18. Spaan JA (2009) The Nightingale Award 2008. Med Biol Eng Comput 47:2

19. Spaan JA, ter Wee R, van Teeffelen JW, Streekstra G, Siebes M, Kolyva C, Vink H, Fokkema DS, VanBavel E (2005) Visualisation of intramural coronary vasculature by an imaging cryomicrotome suggests compartmentalisation of myocardial perfusion areas. Med Biol Eng Comput 43:431-435

20. van Horssen P, Siebes M, Hoefer I, Spaan JA, van den Wijngaard JP (2010) Improved detection of fluorescently labeled microspheres and vessel architecture with an imaging cryomicrotome. Med Biol Eng Comput 48:735-744 